\title{
Proposta de um Instrumento para Análise de Manuais Escolares de Física e Química
}

\section{INTRODUÇÃO}

O objectivo deste estudo é a elaboração de um instrumento para análise de manuais escolares *, M.E., de Física e de Química, com possibilidade de ser utilizado por professores. Tal objectivo decorre de três constataçð̄es.

(i) Os professores de Física e Química (bem como os das outras disciplinas), vêem-se confrontados com a necessidade de tomar decisర̋es sobre o M.E. a adoptar. $\mathrm{O}$ processo de escolha dos manuais escolares tem sido objecto de alguns diplomas legislativos recentes sendo um dos mais polémicos, o Decreto-Lei n. ${ }^{\circ} 108 / 86$, de 31 de Maio, cuja ratificação foi recusada pela Resolução da Assembleia da República n. ${ }^{\circ} 21 / 86$, de 31 de Julho.

A Lei de Bases do Sistema Educativo (Lei n. ${ }^{\circ} 46 / 86$, de 14 de Outubro), no seu Artigo $41 .^{\circ}$, n. ${ }^{\circ} 2$, define os manuais escolares como «recursos educativos privilegiados, a exigirem especial atenção" e no Artigo $44 .^{\circ}$, alinea e) diz ser da responsabilidade da administração central, a "garantia da qualidade pedagógica e técnica dos vários meios didácticos, incluindo os manuais escolares».

O Decreto-Lei n. ${ }^{\circ}$ 57/87, de 31 de Janeiro, fixa o prazo de vigência dos programas curriculares e as normas respeitantes ao processo de apreciação dos manuais escolares. Sobre o último aspecto estabelece este Decreto-Lei que «serão constituídas, no âmbito do Ministério da Educação e Cultura, comissőes de apreciação dos manuais escolares, de âmbito nacional, para cada disciplina e para cada nível dos ensinos básico e secundário», as quais escolherão "até três manuais que, pelas suas qualidades científicas e pedagógicas, mereçam tal opção» (Artigo 3. ${ }^{\circ}$, n. ${ }^{\circ} 1$ e Artigo $4 .^{\circ}$, n. ${ }^{\circ}$ 1). "A aprovação dos manuais escolares para o ano lectivo de 1988-1989 far-se-á em regime experimental, apenas em casos expressamente estabelecidos por despacho ministerial» (Despacho Normativo n. ${ }^{\circ}$ 23/87, de 31 de Janeiro).

No ano lectivo de 1987-1988, o processo de escolha dos manuais escolares processou-se de acordo com o Despacho $16 / \mathrm{EBS} / 87$, de 19 de Fevereiro, o qual estabelece no n. ${ }^{\circ} 1$ que, «a adopção dos manuais escolares será efectuada de acordo com critérios de natureza pedagógica-didáctica e científica, tendo em conta os conteúdos, comunicação e métodos».

\footnotetext{
* Este estudo insere-se no projecto de investigação "O Ensino e a Apredizagem da Fisica e da Química: análise da situação actual no ensino secundáriom, subsidiado pelo Instituto Nacional de Investigaçåo Científica, contrato $n .^{\circ} 85 / C E X / 3$, de 27 de Dezembro de 1985
}

(ii) Não existem instrumentos que permitam dar resposta eficaz a tal tomada de decisão. Com efeito, no que respeita à disciplina de Física e Química, apenas existe publicado um instrumento sucinto que pretende "servir de inspiração aos professores» para a análise de manuais escolares e que deixa ao critério da escola, a interpretação da pontuação a atribuir a cada manual, por cada item em análise (Campos, 1985).

(iii) O M.E. desempenha um papel relevante no processo educativo. A corroborar esta afirmação existem diversos estudos publicados sobre a qualidade, o impacto e a importância dos manuais escolares, bem como a realização, sobre o mesmo assunto, de conferências, simpósios e reunið̄es, em diversos pontos do mundo. Saliente-se o simposio realizado aquando das celebraçōes do $10^{\circ}$ centenário da American Chemical Society, em 1976, em Now York, promovido pela Divisão de Educação em Química, subordinada ao tema «The Influence and Impact of Textbooks on Chemical Education». Foi então expressa a ideia de que «o manual escolar continua a ser um dos principais componentes no processo instrucional em Química» (Shakhashiri, 1977). Na literatura a importância dos manuais escolares é referida, por exemplo, por Dent (1976), segundo o qual estes representam uma das cinco variáveis da prática educacional - «professores, alunos, manuais escolares, curricula, escolas». Um outro autor (Bishop, 1961) refere que os manuais escolares se situam entre os principais meios de difusão do conhecimento sobre uma dada matéria. Tal como os equipamentos audio-visuais e os de laboratório, os manuais escolares são, em extensão variável, auxiliares do professor (Newton, 1983).

A importância da problemática dos manuais escolares reflecte-se num substancial número de estudos publicados na literatura e que se podem classificar em dois grandes grupos.

a) Os estudos de análise semântica de textos de índole predominantemente fundamentalista, normalmente com base na psicolinguística e dirigindo-se a questð̋es como sejam o reportório linguístico do aluno ou a estruturação do seu sistema semântico, dos quais os trabalhos de Ehrlich et al (1982) são um bom exemplo.

b) Os estudos de índole essencialmente pragmática, dirigindo-se a questð̋es educacionais mais de ordem prática relacionadas com a utilização que do M.E. podem fazer os professores e/ou os alunos, e onde se situam a elaboração de grelhas de análise (ver, por exemplo, Richaudeau, 1979).

Esta última é a problemática que nos preocupa no presente estudo.

\footnotetext{
- Departamento de Didáctica e Tecnologia Educativa, Universidade de Aveiro
} 
Refira-se finalmente que, no caso da Física e da Quimica, uma análise mesmo superficial dos manuais escolares publicados nos últimos 30 anos permite detectar modificaçס̄es sensíveis. Tais modificaçø̄es acompanham de perto a evolução havida no ensino das ciências, nomeadamente a partir dos anos 60 com destaque para os "processos da ciência", e na década de 70, a importância dada à interligação Ciência-Tecnologia-Sociedade (Bybee, 1987). Esta evolução relacionada com alteraçסes havidas ao nível dos contextos educacional, social e teórico, veio a traduzir-se em novos objectivos de ensino-aprendizagem das ciências (Fensham, 1980; Orpwood and Souque, 1984; ASE, 1985).

\section{FUNDAMENTAÇÃO DO INSTRUMENTO}

No essencial, os princípios orientadores subjacentes à construção do instrumento de análise basearam-se em três aspectos fundamentais: (i) o modelo de ensino-apredizagem preconizado, (ii) a perspectiva perfilhadas sobre a natureza da Ciência e (iii) a aplicabilidade desse instrumento na selecção do M.E. mais adequado. Apresentam-se a seguir as principais ideias relativas a esses princípios.

(i) $\mathrm{O}$ modelo de ensino-aprendizagem preconizado baseia-se numa teoria do conhecimento de raiz construtivista (Kelly, 1955). Segundo esta, por detrás dos juízos e consequente comportamento dum indivíduo, existe uma teoria implícita acerca do conjunto dos acontecimentos no contexto do qual esses juízos são feitos. Assim, nesta filosofia, é central a perspectiva pessoal. Nela se destacam dois aspectos (1) o comportamento do homem não é guiado pelos instintos, nem determinado por associação entre estímulo e resposta, (2) a aprendizagem significativa só terá lugar se o indivíduo compreender a relevância pessoal da matéria a ser aprendida.

No modelo construtivista do ensino-aprendizagem a construção da realidade é vista, como um processo activo, criativo, racional e emocional, centrado no indivíduo a quem é reconhecido o direito de ter oportunidades que lhes permitam desenvolver-se de modo a poder agir cientificamente na sociedade em que está inserido. Para tal, os conteúdos científicos serão os veículos através dos quais deverão ser desenvolvidas atitudes e capacidades julgadas necessárias para um tal proceder.

Neste modelo uma convicção básica é a de que o aluno é considerado como indivíduo activo e determinado, que está continuamente a construir e a reconstruir os seus conceitos pessoais, por ele usados na aprendizagem em ciência. Outra ideia básica deste modelo é a de que as mentes das crianças, jovens e adultos não se encontram vazias quando formalmente confrontados pela primeira vez com um dado conceito científico. Pelo contrário devido à sua interacção com o mundo que os rodeia construiram já uma «teoria» implícita através da qual explicam e interpretam aquilo que os cerca.

Assim, é preconizado neste modelo de ensino-aprendizagem que o aluno progrida por integração da nova informação num conjunto de ideias prévias ou intuiti-

\footnotetext{
- Entende-se por manual escolar um livro destinado a ser utilizado pelo aluno como recurso didáctico, no ambito da disciplina. Embora tal livro possa tambem ser usado pelo professor, a lógica da construçấo do instrumento de análise centrou-se no aluno como seu utilizador.
}

vas, também designadas por pré-concepções (ver, por exemplo, Ausubel, 1968; Clement, 1982) ou por ciência da criança (Gilbert, Osborne e Fensham, 1982) em direç̧ão a uma visão mais científica do mundo. Este processo implica que tal mudança conceptual esteja criticamente dependente duma abordagem experimental do ensino. Nela o aluno deverá ter oportunidades variadas para usar o seu próprio conceito em desenvolvimento a fim de investigar e explicar os fenómenos naturais. Devem desenvolver-se esforços no sentido de reconhecer este conhecimento prévio e ajudar-se o aluno a reconstruir os seus conceitos através de experiências apropriadas.

Foi esta perspectiva construtivista que decidiu, para a grelha de análise, a selecção de dimensōes tais como Adequabilidade da Comunicação, Clareza da Comunicação, Utilização e Apresentação, que irão ser desenvolvidas na secção seguinte.

(ii) A perspectiva adoptada quanto à natureza da ciência implica que esta seja considerada não como uma acumulação de conhecimentos mas como um processo dinâmico de interpretação dos fenómenos naturais. Dentro desta perspectiva, é de destacar o carácter provisório do conhecimento e a necessidade de reconstrução do mesmo à luz de novos dados, quer experimentais quer teóricos. À filosofia baconiana, segundo a qual o conhecimento era induzido fundamentalmente a partir da observação, isenta de qualquer subjectividade, contrapore-se uma filosofia segundo a qual qualquer observação é dependente do quadro de referência conceptual do observador. Neste contexto, uma abordagem histórica do desenvolvimento das ideias científicas, realçando o seu carácter problemático, e a perspectiva dinâmica dos seus princípios, é vista como suporte à filosofia da ciência preconizada anteriormente. Foi com base nesta perspectiva que se decidiu a inclusão na grelha de análise do parametro Natureza da Ciência.

Um outro aspecto da natureza da ciência considerado é o da interligação Ciência-Sociedade. A ideia de que a educação científica deve considerar essa relação é aqui perfilhada, como, por exemplo, através do uso da informaça científica de uma maneira que seja mais útil ao cidadão na tomada de decisðes, na compreensão e na resolução de problemas do dia-a-dia, numa sociedade de índole tecnológica e com relevância para o contexto nacional. É neste sentido aliás, que apontam objectivos recentes para o ensino das ciências (Yager, 1982).

Tal posição sobre o ensino das ciências, em particular da Física e da Química, foram tomados em conta na grelha de análise, nomeadamente nos parâmetros Contexto Historico, Contexto Socio-Cultural e Contexto Tecnológico.

(iii) No que respeita à sua aplicabilidade o instrumento de análise apresentado foi elaborado de modo a poder ser utilizado pelos professores na selecção do M.E. mais adequado, de entre os manuais considerados para selecção. Daí que se tenham omitido aspectos de relevância secundária e destacado outros recentemente identificados como de grande importância no ensino-apredizagem das ciências, nomeadamente, problemas da linguagem em ciência (ASE, 1980; Johnson, 1979; Newton, 1984), e a dificuldade de articulação entre correcçăo científica e nível de abordagem dos conceitos. 
Tratando-se apesar de tudo de um instrumento detalhado quanto aos aspectos que devem ser tomados em consideração para análise dos manuais escolares de Física e de Química, a avaliação de cada manual será relativamente demorada. Pretendeu-se no entanto torná-la o menos subjectiva possível.

\section{APRESENTAÇÃO DO INSTRUMENTO}

Nesta secção pretende-se apresentar a metodologia na construção do instrumento (3.1), a escolha da escala de avaliação utilizada (3.2) e fazer uma descrição do instrumento (3.3).

\subsection{Metodologia da construção}

A metodologia utilizada para a elaboração do instrumento de análise teve por base a consideração de terminados níveis de generalidade, categorias de análise, os quais foram sendo hierarquicamente discriminados nos níveis seguintes, dimensð̋es, parâmetros e itens.

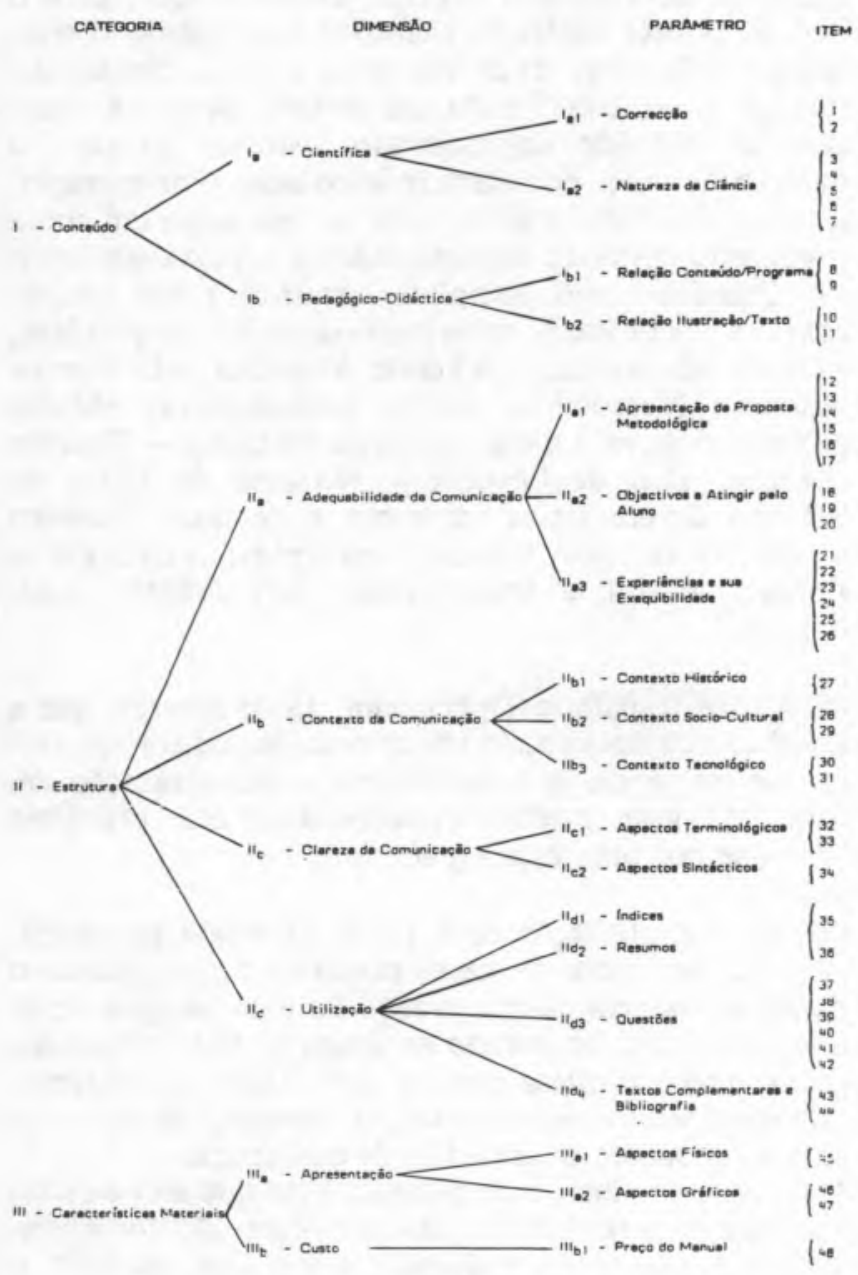

FIGURA 1

Ntveis de análise

Consideram-se primeiramente três categorias as quais agrupam os aspectos mais gerais que podem ser avaliados num M.E.: o seu conteúdo, a sua estrutura e as suas caracteristicas materiais.

Definem-se a seguir estas categorias.

\section{CATEGORIAS DE ANÁLISE}

I - CONTEÚDO: a informação de índole científica e pedagógico-didáctica existente no M.E.

II-ESTRUTURA: os aspectos metodologicos da transmissão do conteúdo

III - CARACTERISTICAS MATERIAIS: os aspectos relativos à apresentação e ao custo do M.E.

Cada uma destas categorias engloba diferentes dimensões de análise, supostas com idênticos níveis de generalidade. Assim, considerou-se que a categoria CON$T E U D O$ podia ser analisada segundo duas dimensðes: a Cientifica e a Pedagógica-Didáctica, que a seguir se definem.

$I_{a}-$ Cientifica: aspectos relacionados com a informação científica: factos/leis/teorias/convençס̃es

$I_{b}-$ Pedagógico-Didáctica: toda a informação que visa integrar o conteúdo científico no contexto educativo

$\mathrm{Na}$ categoria ESTRUTURA consideram-se quatro dimensōes de análise: $\mathrm{II}_{\mathrm{a}}$ - Adequabilidade da Comunicação, $\mathrm{II}_{\mathrm{b}}$ - Contexto da Comunicação, $I_{c}-$ Clareza da Comunicação,e $\mathrm{II}_{\mathrm{d}}-$ Utilização, definidas como se segue:

$I_{a}$ - Adequabilidade da Comunicação: a articulação da comunicação com o fim a que se destina

$I_{b}$ - Contexto da Comunicação: o contexto (histórico, socio-cultural e tecnolbgico) utilizado para a apresentação do conteúdo

$I I_{c}$ - Clareza da Comunicação: os aspectos terminológicos e sintácticos utilizados na comunicação

$I I_{d}$ - Utilização: os aspectos relativos à existência de questðes, de índices, de resumos ou sínteses, por unidade, de textos complementares e de bibliografia

Na categoria CARACTERISTICAS MATERIAIS consideraram-se duas dimensð̄es: III $_{\mathrm{a}}-$ Apresentação, e $\mathrm{III}_{\mathrm{b}}-$ Custo, assim definidas:

III $I_{a}-$ Apresentação: os aspectos relacionados com as características físicas e gráficas

$I I I_{b}$ - Custo: o preço de capa

Cada uma destas dimensð̃es de análise pode englobar, por sua vez, diversos parâmetros de análise assim definidos.

Parâmetros de análise para a dimensão Cientifica

$I_{a l}$ - Correcção: concordância do conteúdo científico com o conhecimento divulgado pela comunidade científica segundo o modelo explicativo adoptado

$I_{a 2}$ - Natureza da Ciência: processo de construção do conhecimento científico

Parâmetros de análise para a dimensão Pedagógico-Didáctica

$I_{b l}$ - Relação Conteúdo/Programa: concordância entre o conteúdo científico do M.E. e o programa em vigor 
$I_{b 2}-$ Relação Ilustração/Texto: características da ilustração usada de modo a clarificar a informação

Parâmetros de análise para a dimensão Adequabilidade da Comunicação

$I_{a l}$ - Apresentação da Proposta Metodológica: natureza da abordagem do programa

$\mathrm{II}_{a 2}$ - Objectivos a Atingir pelo Aluno: explicitação dos objectivos a atingir pelo aluno

$I_{a 3}-$ Experiência e sua Exequibilidade: adequação entre as experiências propostas e as condiçð̃es materiais existentes (materiais de uso corrente, equipamentos alternativos e segurança)

Parâmetros de análise para a dimensão Contexto da Comunicação

× $I_{b l}-$ Contexto Histórico: informação relativa à historia da Ciência e da Tecnologia

$I_{b 2}$ - Contexto Socio-Cultural: informação relativa ao impacto socio-cultural da Ciência (F/Q) e Tecnologia incluindo aspectos éticos das suas aplicaçðes

$I_{b 3}$ - Contexto Tecnológico: informação sobre processos e produtos da tecnologia com destaque para o contexto nacional

Parâmetros de análise para a dimensão Clareza da Comunicação

$I I_{c l}$ - Aspectos Terminológicos: existência de palavras com diversos significados, termos e símbolos novos

$I I_{c 2}$ - Aspectos Sintácticos: tipo de construção gramatical, nomeadamente uso de frases pouco extensas e não utilização de dupla negativa

Parâmetros de análise para a dimensão Utilização

$I_{d l}$ - indices: existência de índice geral e índice de assuntos

$I I_{d 2}-$ Resumos: existência de resumos sintetizando as ideias principais

$I I_{d 3}-$ Questð̃es: existência de questð̋es de diferentes tipos e graus de dificuldade

$I_{d 4}-$ Textos Complementares e Bibliografia: existência de textos e/ou de referências para leituras complementares

Parâmetros de análise para a dimensão Apresentação

$I I I_{a l}$ - Aspectos Fisicos: apresentação de resistência, maneabilidade e dimensø̃es adequadas ao uso frequente

$I I_{a 2}-$ Aspectos Gráficos: qualidade da reprodução, da ilustração e texto

Parâmetros de análise para a dimensão Custo

$I I I_{b l}$ - Preço do Manual: preço de capa

Finalmente consideraram-se em cada parâmetro, diversos níveis operacionais de análise, os itens. Os itens foram definidos de modo a evidenciar os aspectos considerados positivos (por exemplo, item $2-$ "O M.E. esclarece sobre o uso incorrecto de expressð̄es de utilização corrente») relativamente a cada um dos quais se poderá analisar o M.E.

\subsection{Escala de avaliação}

A escala de avaliação utilizada no instrumento de análise é uma escala de frequência de 6 graus.

Os critérios em que se baseou a sua escolha foram os seguintes.

(i) Optou-se por uma escala de frequência que, apresentando menos problemas de subjectividade, permite indirectamente uma avaliação qualitativa dos manuais escolares. Assim, na escala utilizada, os três primeiros graus, nunca, quase nunca e algumas vezes, reflectem uma apreciação negativa do M.E. relativamente a item em análise, e os três últimos, bastantes vezes, quase sempre e sempre, reflectem uma apreciação positiva.

Saliente-se que o grau sempre, (e consequentemente todos os outros) não traduz necessariamente a mesma medição, isto é, não representa o mesmo número de vezes para todos os itens. Por exemplo, para que o item 1- «A informação é correcta do ponto de vista científico, incluindo apresentação de resultados, unidades, exemplos e analogias usadas" - seja classificado no grau 6 - sempre - o M.E. não deverá apresentar qualquer incorrecção científica, enquanto que, para o item $27-$-O conteúdo científico é apresentado sempre que relevante, tendo em conta a sua evolução histórica" - ser classificado em sempre, deverá a inserção do conteúdo no momento histórico ser feita o número de vezes considerado adequado. Por exemplo, no caso da Química do $8 .^{\circ}$ ano deverá ter-se em conta o contexto histórico a propósito dos tópicos seguintes: "A Química como disciplina científica e sua relação com as "práticas" anteriores (por ex. alquímia)"; "Teoria corpuscular»; "Teoria atómica»; "Elementos químicos (descoberta, nome, simbologia)»; "Massa atómica relativa e massa molecular relativa - Padrōes usados»; "Lei de Lavoisier». No caso da Física do 9. ${ }^{\circ}$ ano deverá ter-se em conta o contexto histórico a propósito dos tópicos seguintes: «Energia e Força»; "Calor e temperatura»; "Fenómenos luminosos".

(ii) Vários trabalhos (Oppenheim, 1979) sugerem que a existência de uma escala impar pode introduzir um factor de influência que condiciona a sua utilização em torno do grau médio. Para eliminar este problema optou-se por uma escala par.

(iii) Com a utilização de 6 graus na escala pretendeu-se abranger todos os casos possíveis contemplando o nunca a ausência da observação do item; sempre desde que o item seja observado ao longo de todo o manual; quase nunca e quase sempre significando a existência de excepçðes correspondentes. Os restantes graus representam situaçð̄es intermédias de consecução.

Nos casos dos itens cuja resposta é do tipo sim ou não, usar-se-á o grau nunca quando o item não for observado e o grau sempre quando o for. Por exemplo, o item $18-" \mathrm{O}$ M.E. explicita objectivos gerais que o aluno deverá atingir ao longo do processo ensino-aprendizagem da disciplina».

\subsection{Descrição do instrumento}

Apresenta-se a seguir o instrumento na forma de grelha de análise. 


\section{GRELHA DE ANÁLISE DE MANUAIS ESCOLARES DE FÍSICA E DE QUÍMICA}

Indicam-se a seguir aleatoriamente, para cada parâmetro de análise, os itens discriminados para avaliação. Utilizando a escala indicada, assinale a avaliação que faz de cada item.

Manual:

\begin{tabular}{|c|c|c|c|c|c|c|c|}
\hline 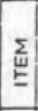 & CATEGCRIA/PARAMETRO & $\frac{5}{2}$ & 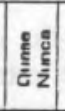 & 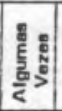 & 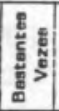 & 高 & 竎 \\
\hline & I- CONTEUDO & & & & & & \\
\hline & Ial - Correç̧ăo & & & & & & \\
\hline 1 & 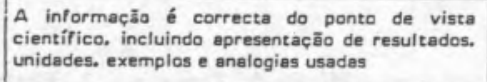 & & & & & & \\
\hline 2 & $\begin{array}{l}\text { O M.E. esciarece sobre o uso incorrecto de } \\
\text { expressōes de utilizaçāo corrente }\end{array}$ & & & & & & \\
\hline & la2 - Natureza da Ciência & & & & & & \\
\hline 3 & $\begin{array}{l}\text { A diferença entre realidade e modelo explicati- } \\
\text { vo. facto e teoria. é estabelecida de forma } \\
\text { ineauivoca }\end{array}$ & & & & & & \\
\hline 4 & 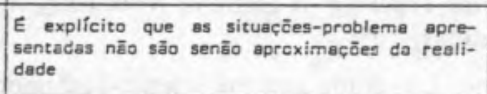 & & & & & & \\
\hline 5 & $\begin{array}{l}\text { As interpretaçōes apresentadas sãa referidas } \\
\text { em termos da sua validade temporal }\end{array}$ & & & & & & \\
\hline 6 & $\begin{array}{l}\text { Oâo-se exemplos de problemas não resolvidos } \\
\text { em investigaça ou que necessitem de ser } \\
\text { investigados }\end{array}$ & & & & & & \\
\hline 7 & $\begin{array}{l}\text { As experiêncies referidas no M.E. são precedidas } \\
\text { de justificaçẫo do porquê da sua realizaçâa }\end{array}$ & & & & & & \\
\hline & Ib1 - Relaçäo Conteúdo - Programa & & & & & & \\
\hline 8 & $\begin{array}{l}\text { O tratamento de conceitos não inclú́dos no } \\
\text { programa, ac longo do texto e em textos comple- } \\
\text { mentares, é relevante para a compreensấo }\end{array}$ & & & & & & \\
\hline 8 & $\begin{array}{l}\text { A extensão e a profundidade de informaçäo } \\
\text { posta no tratamento dos conceitos é equilibrada } \\
\text { tendo em conta o programa no seu todo }\end{array}$ & & & & & & \\
\hline & Ib2 - Relaçäo Ilustreçäo - Texto & & & & & & \\
\hline 10 & $\begin{array}{l}\text { A ilustração está inclúida próxima do local } \\
\text { onde é referida e é claramente referencieda }\end{array}$ & & & & & & \\
\hline 11 & $\begin{array}{l}\text { Os aspectos referenciados no texto que preten- } \\
\text { dem ser destacados através da ilustraçấo sấo } \\
\text { inequivocamente ressaltados nesta }\end{array}$ & & & & & & \\
\hline & II - ESTRUTURA & & & & & & \\
\hline & $\begin{array}{l}\mathrm{I}_{\mathrm{B} 1} \text { - Apresentaçāo da Proposta } \\
\text { Metodológica }\end{array}$ & & & & & & \\
\hline 12 & $\begin{array}{l}\text { A abordagem é feite de modo a que primeiro } \\
\text { é discutida a ideia e só depois é introduzido } \\
\text { onome }\end{array}$ & & & & & & \\
\hline 13 & $\begin{array}{l}\text { A abordagem dos conceitos é feita. desde } \\
\text { que viável. com suporte experimental }\end{array}$ & & & & & & \\
\hline 14 & $\begin{array}{l}\text { A apresentaçāo dos conceitos está articulada } \\
\text { com conceitos pré-requisitos }\end{array}$ & & & & & & \\
\hline 15 & $\begin{array}{l}\text { As estratégias utilizades promovem o desen- } \\
\text { volvimento de capacidades científicas tais } \\
\text { como observaço. formulaça de hipóteses. } \\
\text { planeamento de experiências. análise critica } \\
\text { de resultados }\end{array}$ & & & & & & \\
\hline 18 & $\begin{array}{l}\text { As estratégies utilizadas promovem o desen- } \\
\text { volvimento de atitudes científicas tais como } \\
\text { honestidede intelectual. tolerância. abertura } \\
\text { a mudança }\end{array}$ & & & & & & \\
\hline 17 & 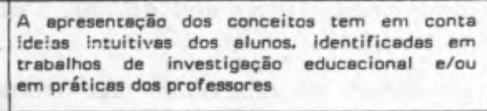 & & & & & & \\
\hline
\end{tabular}

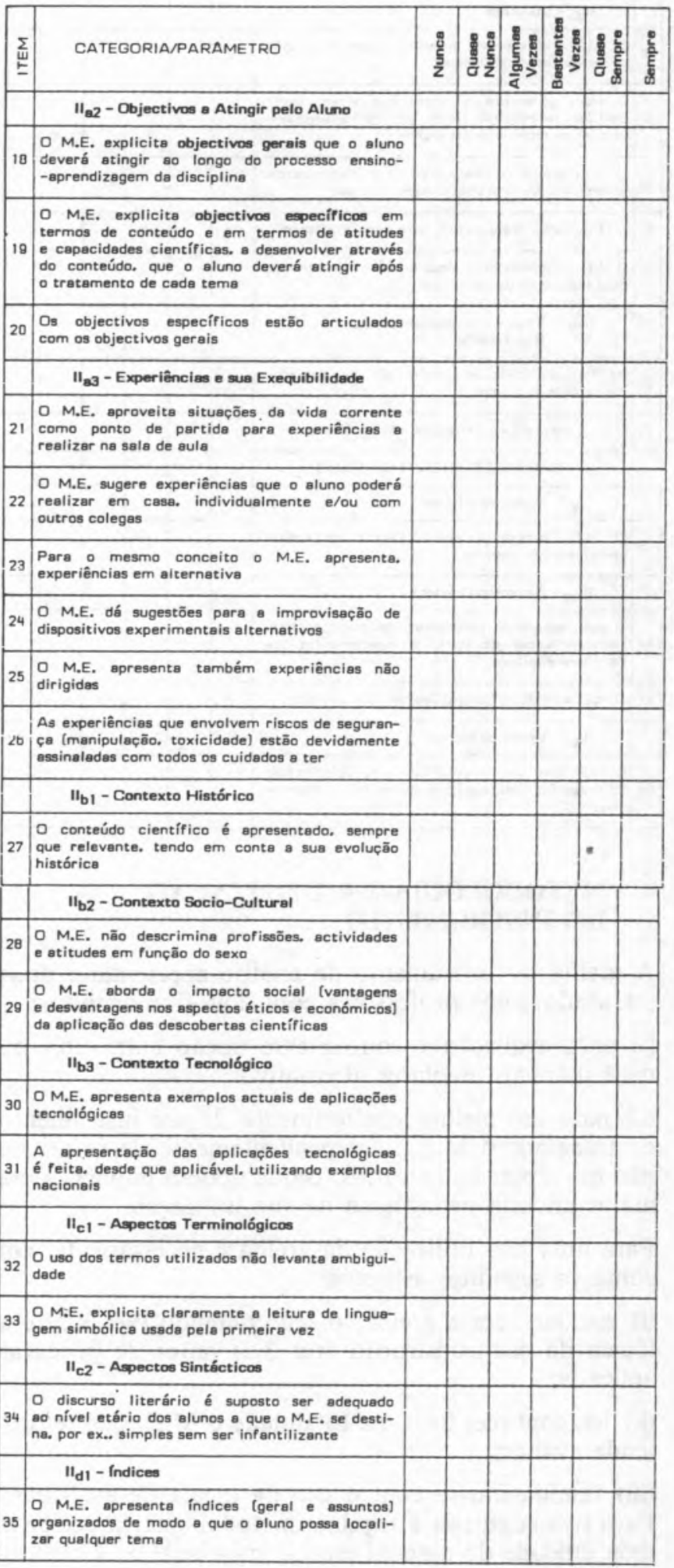




\begin{tabular}{|c|c|c|c|c|c|c|c|}
\hline$\underset{\underline{\underline{E}}}{\Sigma}$ & CATEGORIAMPARAMETRO & $\frac{8}{2}$ & $\frac{9}{8}$ & 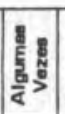 & 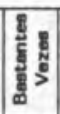 & व & है \\
\hline & IId2-Resumos & & & & & & \\
\hline \multirow[t]{2}{*}{36} & $\begin{array}{l}\text { O M.E. apresenta resumos. sintetizando as } \\
\text { ideies principais (sem apresentar definições) }\end{array}$ & & & & & & \\
\hline & "d3 - Questōes & & & & & & \\
\hline \multirow[t]{2}{*}{37} & $\begin{array}{l}\text { o M.E. apresenta questões que promoverm } \\
\text { a aprendizagem de simbolos e convençốes }\end{array}$ & & & & & & \\
\hline & "13 - Questōes & & & & & & \\
\hline 38 & $\begin{array}{l}\text { O M.E. apresenta questões para avaliação } \\
\text { de capecidades científicas }\end{array}$ & & & & & & \\
\hline 39 & $\begin{array}{l}\text { O M.E. apresenta questốes que visam gerar } \\
\text { conflito conceptual tendo em conta presumi- } \\
\text { veis ideias intuitivas dos alunos }\end{array}$ & & & & & & \\
\hline 40 & $\begin{array}{l}\text { O M.E. propõe a realização de mini-projectos. } \\
\text { de ordern documental e/ou experimental }\end{array}$ & & & & & & \\
\hline 41 & O M.E. apresenta questōes para auto-avaliação & & & & & & \\
\hline \multirow[t]{2}{*}{42} & $\begin{array}{l}\text { O M.E. apresenta problemas numéricos resolvidos } \\
\text { para ilustração de conceitos }\end{array}$ & & & & & & \\
\hline & $\begin{array}{l}\|_{\mathrm{d} 4} \text { - Textos Complementares e } \\
\text { Bibliografia }\end{array}$ & & & & & & \\
\hline 43 & $\begin{array}{l}\text { As leituras complementares săo devidamente } \\
\text { essinalades no texto }\end{array}$ & & & & & & \\
\hline \multirow[t]{3}{*}{44} & O M.E. apresenta referências bibliográficas & & & & & & \\
\hline & III- CARACTERISTICAS MATERIAIS & & & & & & \\
\hline & $\mathrm{III}_{\mathrm{al}}$ - Aspectos Físicos & & & & & & \\
\hline \multirow[t]{2}{*}{45} & $\begin{array}{l}0 \text { M.E. apresenta resistência e dimensōes } \\
\text { apropriades ao seu uso }\end{array}$ & & & & & & \\
\hline & IIII2-Aspectos Gráficos & & & & & & \\
\hline 46 & $\begin{array}{l}\text { O M.E. apresenta caracteres tipográficos (tipo. } \\
\text { tamanho e cor de letra] e espaçamentos que } \\
\text { facilitam a leitura }\end{array}$ & & & & & & \\
\hline \multirow[t]{2}{*}{47} & O M.E. apresente ilustraçōes bem reproduzidas & & & & & & \\
\hline & III $\mathrm{b}_{\mathrm{1}}$ - Preço do Manual & & & & & & \\
\hline 4e & $\begin{array}{l}\text { O M.E. tem um preço próximo do valor médie } \\
\text { do preço (actualizado) dos outros M.Es. alterna- } \\
\text { tivos }\end{array}$ & & & & & & \\
\hline
\end{tabular}

\section{METODOLOGIA DA UTILIZAÇÃO DO INSTRUMENTO}

A grelha ou instrumento de análise apresentado pode ser usado pelos professores com dois fins distintos:

(i) para avaliação e consequente opção entre dois ou mais manuais escolares alternativos;

(ii) para um melhor conhecimento de um instrumento de trabalho, o M.E., independentemente de se ter ou não que optar entre vários, o que poderá implicar uma maior eficácia pedagógica na sua utilização.

Para uma boa utilização da grelha é necessário ter em conta os seguintes aspectos:

(i) estudar bem a grelha, o seu conteúdo (ver 3.2) e a lógica da sua construção (ver 3.1) antes de procurar aplicá-la;

(ii) ler/conhecer bem, na totalidade o M.E. que se pretende avaliar;

(iii) familiarizar-se com o uso da escala de avaliação. Para isso sugere-se a seguinte metodologia. Seleccionar uma unidade do manual escolar para análise. Começar por fazer, para cada item, um reconhecimento global. Fazer em seguida uma apreciação na escala quantitativa, de 6 graus (ter em atenção que a maior parte dos itens só poderá ser avaliada tendo em conta o livro no seu todo, isto é, não são observáveis em parte do M.E.); (iv) se possível comparar a pontuação atribuída com a de outro(s) avaliador(es), a fim de aferir critérios de fidelidade. Em caso de divergência entre os resultados será conveniente discutir as razōes que estiveram na base da classificação atribuída por cada um;

(v) a qualidade de M.Es. alternativos, pederá, caso necessário, ser traduzida quantitativamente, de acordo com a seguinte correspondência: «nunca» -0 pontos; "quase nunca» -1 ponto; ...; «sempre» -5 pontos;

(vi) poder-se-ão comparar M.Es. alternativos relativamente a cada parâmetro somando as pontuaçð̃es obtidas em cada uma dos itens correspondentes.

\section{REFERÊNCIAS}

ASE, 1980. Language in Science, ASE Study Series n. ${ }^{\circ}$ 1, Hatfield ASE, 1985. Planning for Science in the Curriculum, ASE Occasionel papers, Hatfield

Ausubel, D.P., 1968. Educational Psychology: A cognitive view, New York, Hotl, Rinehart and Winston

Bishop, G.D., 1961. Physics Teaching in England from early times up to 1850, PRM Publications, 105

Bybee, R.W., 1987. «Science Education and the Science-Techonolgy-Society (S-T-S) Theme», Science Education, 71, 667-683

Campos, C.A.C., 1985. "A escolha de um manual escolar", Boletim, Sociedade Portuguesa de Química, 19, 24-26

Gilbert, J.K., Osborne, R.J., Fensham, P.J., 1982. "Children's Science and ist Consequences for Teaching", Science Education, 66, 623-633

Clement, J., 1982. "Students' Preconceptions in Introductory Mechanics», American Journal of Physics, 50, 66-71

Dent, K. (ed.), 1976. Victoria Education, London, History of Education Society, 34

Ehrlich, S., Passerault, J.M., Personnier, G., 1982. Levels of functionning in semantic memory and levels of comprehension of texts. In A. Flammer e W. Kintsch (eds.), Tutorials on text processing, Amsterdan, North-Holland Publishing Company

Fensham, P.J., 1980. "A Research base for new objectives of sciences teaching", Research in Science Education, 10, 23-33

Herron, J.D., 1984. «Using Research in Chemical Education to Improve my Teaching", J. Chem, Educ., 61, 850-854

Johnson, R.K., 1979, «Readability», S.S.R., 60, 562-568

Kelly, G.A., 1955. The Psychology of Personal Construct, New York, Norton

Kneller, G.F., 1980. A Ciência como actividade humana, Rio de Janeiro, Zahar Editions, S. Paulo, Editora da Universidade de S. Paulo

Newton, D.P., 1983. "The sixth-form physics textbook 1070-1980", Physics Education, 18, 192-198

Newton, D.P., 1984. «Science textbooks and readability measures - a caveat", S.S.R., 66, 368-371

Orpwood, G.W.F., and Souque, J.P., 1984. Science Education in Canadian Schools, Volume I, Introduction and Curriculum Analyses, Science Council of Canada, Background Study, 52

Oppenheim, A.N., 1979. Questionnaire Design and Attitude Measurement, London, Heinemann

Richaudeau, F., 1979. Conception et production des manuels scolaires/guide pratique, Paris, Unesco

Shakhashiri, B.Z., 1977. "The influence and Impact of Textbooks on Chemical Education", J. Chem. Educ., 54, 266-272

Yager, R.E., 1982. "Factors involved with qualitative syntheses: a new focus for research in science education", Journal of Research in Science Teaching, 19, 337-350 